\title{
Packaging Compromised
}

National Cancer Institute

\section{Source}

National Cancer Institute. Packaging Compromised. NCI Thesaurus. Code C92093.

Problems that occurred because of a compromised packaging of the device (e.g. broken or incomplete seal). 